\title{
Building National Healthcare Infrastructure: The Case of the Danish e-Health Portal
}

\author{
Tina Blegind Jensen and Anne Asmyr Thorseng
}

\subsection{Introduction}

Sundhed.dk facilitates patient-oriented digital services which provide access to and information about the Danish healthcare services. Since its launch in 2003, sundhed.dk provides several functionalities such as quality assured health information, access to medical records and medication, and an overview of the Danish healthcare system. Sundhed.dk creates linkages between existing data sources, opens up data sets to new user groups, and facilitates communication between healthcare providers and citizens. The portal also ensures further development not only by providing a secure infrastructure, search optimization, and user interfaces, but also by supporting the development of new services.

Sundhed.dk has earned good reputation and high standing in the healthcare sector internationally. Health authorities from other countries, that wish to build similar solutions, have approached sundhed.dk for advice and best practice (Sundhed.dk 2014a). However, the positive reputation and high level of maturity of sundhed.dk has not been established overnight. Thus the assumption by other countries of simply copying the code, the user interface, and the technical infrastructure is far too simplistic if they wish to attain what Denmark has achieved with respect to e-health services for citizens. Other infrastructural resources in place, including existing systems, regulations, communication standards, as well as organizational structures in the Danish healthcare sector, have played a vital role in establishing the national

\footnotetext{
T.B. Jensen $(\triangle)$

Department of IT Management, Copenhagen Business School, Howitzvej 60, 2000 Frederiksberg, Denmark

e-mail: blegind@cbs.dk
}

\author{
A.A. Thorseng \\ Department of Informatics, University of Oslo, \\ Gaustadalléen 23 D, Blindern, 1080 Oslo, Norway \\ e-mail: athorseng@gmail.com
}


e-health infrastructure (Thorseng and Jensen 2015). Consequently, the design, development, and implementation of an e-health initiative such as sundhed.dk, that has become an integrated part of a national infrastructure, becomes relevant to study.

In line with the aim of the book, this case chapter provides insights into the role of the installed base - i.e., pre-existing technologies, regulatory frameworks, data resources, and organizational arrangements - in the evolution of sundhed. $\mathrm{dk}$. In particular, we argue that the main reasons for the current positioning of sundhed.dk have been its ability to (1) collate and assemble existing data resources, (2) repurpose and enhance current data sources in the health sector, and (3) engage a multiplicity of stakeholders. We argue that these activities represent three ways of capitalizing on the installed base that has led to the evolution and current situation of the e-health portal. At the same time, we show how these three modes come with a number of challenges for sundhed.dk in its pursuit of further innovation.

The rest of the chapter is organized as follows. We start out by introducing the Danish healthcare sector to set the context for sundhed.dk. Further, we describe the development of sundhed.dk, its purpose, as well as its current organization. Based on this description, we analyze how the organization behind the e-health portal succeeded in establishing a national healthcare infrastructure by assembling existing data resources, repurposing current healthcare services, and mobilizing key stakeholders. We conclude the chapter by providing some thoughts on the future for sundhed.dk.

\section{Method}

The empirical material for this chapter stems from 13 semi-structured interviews conducted between March and October 2014 with staff at the central office of sundhed.dk as well as with partners from the regions, ministry, and other health authorities in Denmark. In addition, we have included documents in the form of press releases, official papers, internal documents, and online information. Three representatives from the sundhed.dk office have read the chapter and verified its content before publication.

\subsection{The Danish Healthcare Sector}

Denmark is like other Scandinavian countries known for its comprehensive welfare system. Denmark provides free and equal access to public healthcare services to its relatively small population of 5.6 million inhabitants. Accordingly, access to all public hospitals as well as general and specialized practitioner services is financed through general taxes. Dentists, out of hospital medicines, as well as some therapies are provided under co-payment or private models on a case basis. The public healthcare system is organized in primary healthcare and the hospital sector. Primary healthcare deals with general health problems and consists of general practitioners 
(GPs), practicing specialists, dentists, physiotherapists, nursing homes, dental care for children, and preventive health schemes. The hospital sector handles medical conditions that require specialized treatment and intensive care. Patients are referred to the hospital by their GP unless it is acute illness or accident. Patients have the right to choose between all public hospitals for treatment, and since 2002, they also have the right to choose a state financed treatment at a private hospital if waiting times are exceeded.

The healthcare system in Denmark is predominantly public and governmentcontrolled through comprehensive legislation and annual budgetary allocations. The Ministry of Health has a coordinating and supervisory role, but operational responsibilities are embedded in a decentralized administrative structure consisting of 5 regions and 98 municipalities (Pedersen et al. 2012). The regions are responsible for the everyday operation of hospitals and primary care. At a national level, the interest organization - Danish Regions ${ }^{1}$ - coordinates the common interests of the five regions and negotiates the annual financial framework for the regions with the government, as well as with the private practicing sector. The municipalities are in charge of public health, homecare, nursing homes, school health service, rehabilitation, and social services. The ambition is to provide a healthcare system that is efficient, of high quality, and that enables free choice of provider by its citizens. In 2015 , the annual government healthcare expenditures amounted to 150 billion DKK (equivalent to 20 billion euros).

The Danish healthcare sector relies heavily on information technology for the provision of healthcare. More than $95 \%$ of the Danish population have access to the internet, and broadband penetration is among the highest in Europe (Danish Regions 2010). A unique personal identifier (CPR number) is issued to all Danish citizens at birth, and citizens can obtain a secure web-ID (NemID) free of charge to access public sites with e-services. Denmark is a small country in terms of population and geographic area; yet, it is at the forefront in the digitalization of medical information and in electronic healthcare record management. Centralized databases store medical information of Danish citizens, including hospitalization information and prescription history. GPs, hospitals, and pharmacies are electronically connected to handle patient records, e-prescriptions, lab results, discharge letters, and electronic referrals to hospitals and specialists (Protti and Johansen 2010). In 2014, $97 \%$ of laboratory test results were delivered online, and $100 \%$ of prescriptions were transmitted to pharmacies electronically.

The high level of digitalization of the Danish healthcare sector can be explained partly by the early development of communication standards ${ }^{2}$ initiated in the mid1990s for the common communication flows between medical practices, hospitals, and pharmacies, as well as the secure Danish Healthcare Data Network. In addition, over the last decade, the Danish government has initiated and sponsored a number

\footnotetext{
${ }^{1}$ Danish Regions is the interest organization for the five regions in Denmark.

${ }^{2}$ MedCom was established in 1994 as a public funded, non-profit cooperation. It facilitates the cooperation between authorities, organizations, and private firms linked to the Danish healthcare sector.
} 
of initiatives to increase the digitalization of its healthcare services. National healthcare digitalization strategies have been published since 1996 to set the agenda for e-health initiatives. One such initiative is the Danish national e-health portal, sundhed.dk, which provides access to and information about patient-oriented digital services in the Danish healthcare sector. Next, we describe the purpose of sundhed.dk, its evolution, as well as its current organization. This description serves as background information for analyzing how sundhed.dk managed to capitalize on its installed base to become what it represents today.

\subsection{Case Narrative: Sundhed.dk}

\subsubsection{Purpose of Sundhed.dk}

The purpose of sundhed.dk is to consolidate relevant information from all parts of the healthcare service and establish an electronic gateway for citizens and healthcare providers to the Danish healthcare system. The ambition is to empower patients by offering insight into and transparency of healthcare services, as well as to offer healthcare professionals easy access to clinical information about their patients. Since its launch in 2003, the objective of sundhed.dk has been to obtain better coordination across healthcare services by providing a government-controlled entry to health information across a relatively decentralized healthcare system. At a strategic level, the ambition is to encourage a common strategy, investments, and solutions for the healthcare services at a national level and to integrate healthcare services on the internet (Sundhed.dk 2016).

Sundhed.dk is at the forefront of governmental e-health portals (Sundhed.dk 2014b), and it serves as a unified hub for electronic communication between patients and healthcare providers. The portal is sector-wide in terms of its governing structure as well as the several national and regional solutions it encompasses. The e-health portal is presented as a central component for patient-oriented digital services in the national healthcare digitization strategies (The Danish Government et al. 2008, 2012).

Internationally, sundhed.dk is recognized for its provision of patient-oriented digital services at a national level. Other countries turn to the central office of sundhed.dk to learn from their experience. However, the development of sundhed.dk - as we know it today - was built step-by-step over a number of years, as we describe next.

\subsubsection{Timeline of Sundhed.dk}

In 2001, the Association of County Councils in Denmark and the Ministry of Interior and Health initiated the work of establishing a common public e-health portal. The various stakeholders in the healthcare sector agreed on the prospect of establishing a common infrastructure and a shared system across municipalities and regions all 


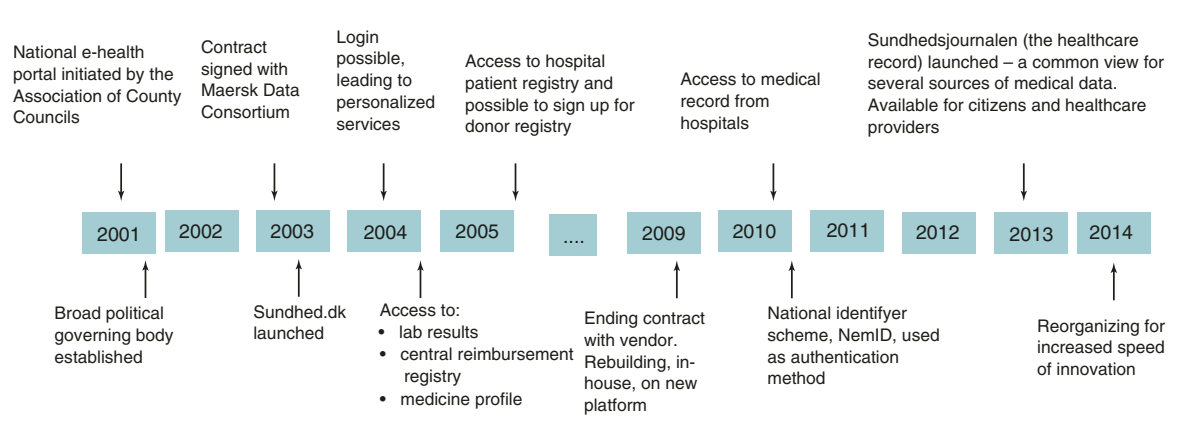

Fig. 13.1 Timeline of main events

over Denmark. Figure 13.1 shows the timeline of the main events that led to and further triggered the development of sundhed.dk.

A broad political governing body, consisting of The Association of County Councils, The Ministry of the Interior and Health, The Greater Capital's Hospital Association, as well as Copenhagen and Frederiksberg Municipalities, was established to support the start of the e-health portal. One of the first tasks for the board of directors was to prepare a tendering process. Due to the scope and complexity of establishing the common infrastructure, it was decided to carry out the tender as a contest, which was launched in spring 2002. The winner of the contest was Maersk Data Consortium consisting of LEC, ACURE, PLS/Ramboll and Bysted with whom the central office of sundhed.dk signed a contract in the beginning of 2003. An analysis of the needs and the development of the first version of the e-health portal was carried out before its launch in December 2003.

In the initial phase of sundhed.dk, the purpose was to add quality-assured medical information that would serve both citizens and healthcare providers. Information about waiting lists at certain hospitals soon became available on the portal. At the beginning of 2004, the functionality of sundhed.dk was expanded with services that require login with a digital signature. A first attempt was made with electronic access to lab results for healthcare providers by connecting to a subset of lab systems already in use in Denmark. From 2004, patients were able to view their electronic medicine profile online. The prescription solution built on an already existing solution called "Medicine Profile" provided by the Danish Health and Medicine Authorities. Later, in 2014, this solution was phased out and replaced by a new solution for prescription handling called "Common Medicine Card" provided by the Danish Public Health Institute. An electronic guidance to the healthcare service was established and it was possible to search for healthcare providers, i.e., GPs, physiotherapists, and psychologists, based on location and availability. Finding their GP on sundhed.dk, patients would be directed to the GP website to initiate booking of appointments and conducting email consultations. Since vendors of booking and email-consultation solutions already had a strong market position, the partners of sundhed.dk agreed to directing patients to the GPs' own sites, where they could access their GP's solution for booking and e-consultation. 
By 2005, patients were able to access the Danish National Patient Registry in which all treatments performed in the hospital sector were listed. This registry, created in 1977, contains personal data about all patients admitted to hospital since 1977, and from 1995 also out-patients registrations (Lynge et al. 2011). Additionally, based on the Central Reimbursement Registry, information about all treatments a patient had received in the public health service were accessible to the patient. By 2006, doctors in 11 out of 19 counties could check online lab results via sundhed.dk. By the end of 2007, the portal had about 170,000 unique users every month.

In April 2009, sundhed.dk was launched on a new technical platform, which meant that the central office gained more control over the portal and reduced costs by being independent of external consultants and developers. This process was described by staff as "taking the portal home" (head of staff, sundhed.dk). Subsequently, a development department now did most development of services in-house, while external consultants were approached to develop standalone services. Apart from smaller developments, there were two major initiatives in this period. One initiative was to make medical records from public hospitals available so that patients would be able to see parts of their medical record such as treatments, diagnoses, and notes made by the healthcare personnel. The e-record was created to ensure information sharing across regions and hospitals; for example, if a patient from Copenhagen were admitted to another region of the country, doctors would now have access to data from previous treatments. The e-record was thus a read-only repository that supplemented the local electronic healthcare information with information from other areas. An important milestone for sundhed.dk, in 2010, was managing access to the portal via NemID. Citizens could now use the same authentication method as banks and other public Danish agencies. This meant that single sign-on was enabled and users needed to remember only one password. In 2015, approximately four million Danes had a NemID account (NemID 2014) and could thus potentially log onto sundhed.dk.

Another major initiative in this period was the healthcare record (sundhedsjournalen) launched in 2013. This initiative enabled a 'one-stop-view' for both patients and healthcare providers with access to medical data such as records stemming from the e-record described above, medicine data, and other critical health information.

\subsubsection{Sundhed.dk Organization}

Sundhed.dk is organized around key stakeholders in the healthcare sector. It consists of a secretariat (i.e., the central office which in 2016 counted 45 employees) and a number of partners that contribute to the development of the portal. The organization is illustrated in Fig. 13.2.

The stakeholders (see the left box) contribute to sundhed.dk through participation in governance activities, projects, and by providing content such as information 


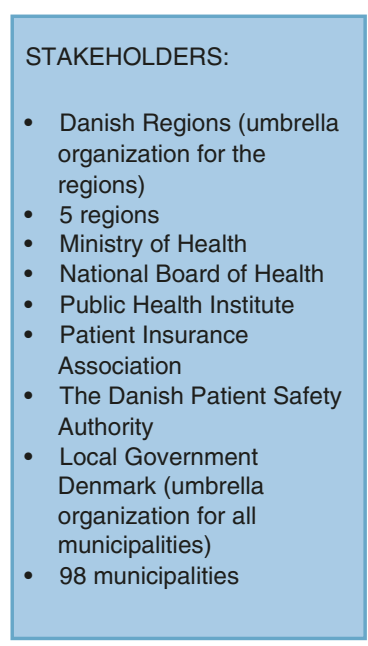

Contribute through

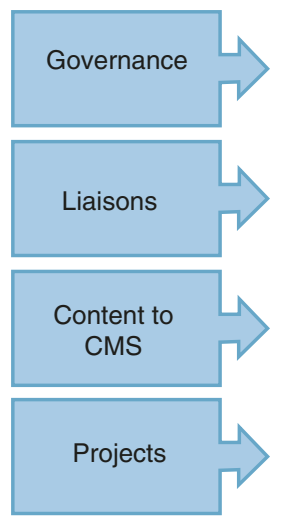

Sundhed.dk SECRETARIAT

Political governing body:

Representatives from:

- The regions

- Ministry of Health

- The municipalities

Steering commitee:

Representatives from:

- Sundhed.dk

- Danish Regions

- All 5 regions

- Ministry of Health

- Local Government Denmark

Observers:

- MedCom

- National Health IT

Group of liasons

Editorial group

Group for the municipalities

Fig. 13.2 Organization of sundhed.dk

about their activities, updated guidelines, etc. The secretariat in sundhed.dk (see the right box) is responsible for administration, marketing, maintenance, and daily running of the portal. The secretariat further comprises a team of assisting partners that take part in conceptualizing and developing new solutions. A political governing body with representatives from Danish Regions, the Ministry of Health, and the municipalities, as well as a steering committee with representatives from the main areas in healthcare are responsible for the overall strategy and prioritization of services and funds.

Health data and services provided through sundhed.dk is based on displaying already existing data from various sources. In some cases, data is being extracted from data sources such as hospital systems, GP systems, prescription databases, and lab systems to be presented through sundhed.dk's presentation layer. In other cases, services are "framed" to achieve sundhed.dk's 'look and feel' although the service is located and run somewhere else. Lastly, sundhed.dk also points or directs users to other existing services in the healthcare sphere, such as booking of appointments for GPs. Figure 13.3 illustrates the architecture of sundhed.dk.

Security is maintained with patient login by means of the national electronic identifier scheme, NemID. Health personnel can access patient data provided through sundhed.dk in their electronic medical records. Health personnel's access to patient data is restricted by ensuring there is an existing treatment relation between patient and health personnel and further that the patient approves health personnel access. Access to patient data by the health personnel is logged and the logs are available to the patient. 


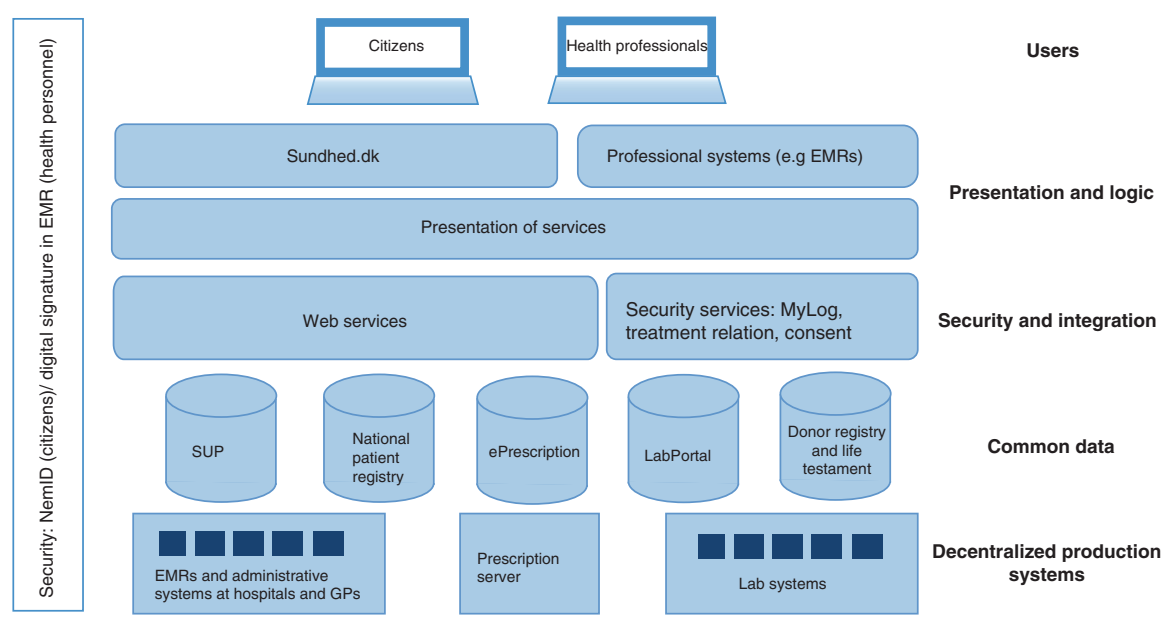

Fig.13.3 Sundhed.dk architecture

\subsection{Analysis: Three Modes of Capitalizing on the Installed Base}

The introduction to sundhed.dk gives an indication of how the organization draws upon, recombines, and repurposes existing technical, legislative, and organizational resources and services. In this section, we detail how the organization of sundhed. dk has: (1) collated and assembled existing data resources, (2) repurposed and enhanced current data sources in the health sector, and (3) engaged multiple stakeholders to obtain its current position. The three modes of capitalizing on the installed base have corresponding opportunities and challenges that we present below.

\subsubsection{Collate and Assemble Existing Data Resources}

Sundhed.dk explicitly aims to provide access to health information, and several of their services involve a collation of pre-existing data sources: "Our ambition is to collect data and to establish easy access to data" (head of administration, sundhed. $\mathrm{dk}$ ). One example of collated data is 'sundhedsjournalen,' where various data sources, such as lab results, prescriptions, and medical records from hospitals are displayed in one view for the citizen and health personnel. In 'sundhedsjournalen,' citizens can also access laboratory results, and they can register for organ donation, as well as set up their living will.

Another example of collated data is the functionality, whereby all healthcare providers are listed with details about opening hours, core services, email consultations, renewal of e-prescriptions, etc. Patients can get information about and overview of healthcare providers, and they can gain direct access to their websites through the portal. 
A third example is the collection of quality-assured health information. The assembling of data sources enhances the value and usefulness of singular data sources in terms of providing easy access to as well as a contextualizing of information. For example, in the case of 'sundhedsjournalen,' data from one source is shown in relation to another. This means that a patient or health professional can see where a patient has been admitted, and at the same time, they can gain access to prescribed medications and discharge notes.

Displaying information to patients relies on laborious work conducted over several years to achieve extraction of data from multiple sources. A representative from one of the regions argued: "Some of these services already existed such as the Landspatientregisteret [The National Patient Registry], so basically, in Denmark, we had an existing infrastructure that was useful when establishing sundhed.dk". In addition, Denmark has a well-established IT infrastructure such as the common standard for health message exchange and the secure Danish healthcare network. This infrastructure has been a prerequisite for the success of sundhed.dk: "In Denmark, we have a strong tradition of digitalization and many solutions were already established locally - let the thousand flowers bloom" (representative, $\mathrm{SSI}^{3}$ ). In other words, the informant argued that, opposed to centrally directed development of digital services in the healthcare sector, local initiatives have been the source of many current information systems. For example, the e-record builds on a mature infrastructure that was the outcome of the project, initiated in 2000, called 'Standardized pull of patient data' (SUP). This database was built to make registered patient data in EPR systems, the Patient Administrative Systems (PAS), and other systems on currently and previously admitted patients available in other hospitals across the country. Initially, SUP provided a majority of hospitals and GPs across Denmark with the possibility of accessing electronic health records across counties. Extracts of patient data are transferred via a nationwide MedCom XML standard to a SUP database/ Internet server, where an Internet browser provides access for healthcare professionals to view selected patient information and record data by searching on the patient's civil registry number (Aanestad and Jensen 2011; Jensen 2013). The head of administration at sundhed.dk explained: "We have 'buttoned on' services and applications over time [...]. We had no ambition of developing something new... rather, we wanted to enable access and gather what already existed [...]. So, basically what we do is to develop a user interface that covers all existing solutions and then make data available from there" (head of administration, sundhed.dk).

Collating and assembling already existing data sources provides easy access to a number of health services for citizens and healthcare professionals; however, it also comes with some challenges. For example, collecting and publishing qualityassured health information and information about the healthcare services requires comprehensive quality control: "More and more quality requirements are being posed from our side [sundhed.dk]. At some point, the amount of editorial content on sundhed.dk was simply overwhelming and then we started talking about quality" (head of administration, sundhed.dk).

${ }^{3}$ SSI stands for 'Statens Serum Institut', National Institute for Health Data and Disease Control. 
Similarly, the organization of sundhed.dk needs to adhere to national regulations and procedures, including pre-existing legal frameworks concerning data ownership on how data is treated and how it can be displayed and accessed. The organization needs to take into account these regulations and therefore it engages in close collaboration with authorities when displaying these data. For example, displaying a collection of medical information to the patient is based on existing legislation on the right to view own health information, in which a person over the age of 15 has the right to see what is being written about him/her. Requesting a physical copy of one's record directly from the hospital requires that the medical staff perform an evaluation of what is disclosed to the patient to avoid distributing sensitive material. However, when making the records available to citizens through the e-health portal, this professional "filter" is no longer present. Through discussions with the health authorities, and interpretation of the existing law on information access, a 14-day delay has been implemented on availability of records to the patient (this delay has been further reduced to 3 days in 2015). This way, health staff can communicate and explain results to the patient before he or she accesses them online. Health personnel on the other hand can access the patient's data immediately.

\subsubsection{Repurpose and Enhance Current Data Sources in the Health Sector}

Part of the ambition of sundhed.dk is to create access to current healthcare data sources, not to "reinvent the wheel" (head of administration, sundhed.dk). Some of the first services on the portal provided access to existing registries. Several of the data sources, which are displayed through sundhed.dk, were originally intended for other purposes than citizen access.

For example, the central reimbursement registry mainly ensures that health providers are reimbursed for the services they provide to patients. The registry serves administrative and research purposes. Another registry is the National Patient Registry whereby a range of data is recorded about patients when they receive care as part of the specialist healthcare service. The data is used for several purposes; for health research, surveillance of diseases, activity monitoring at the hospital, and to estimate and review the total use of hospital services across counties and regions (representative, SSI). Through building on already existing data sources by giving a new user group access, new use of the data is enabled. Through sundhed.dk, patients can use the same data to get an overview of their treatments and movements around the health service.

Second, a gradual expansion of linking to new registers and systems has taken place, and in some instances, sundhed.dk has not only displayed the data, but also enhanced the underlying systems. One example is the donor register; in 1990, legislation was passed defining the legal criteria for being brain dead, which meant that donating organs, besides kidneys, could be performed. Consequently, a donor registry was established to keep track of potential donors. By 2005, an electronic sign-up 
option for the donor registry was created. This means that patients can now register whether they allow all or no organs to be donated, whether they want only some organs to be donated, or whether the decision is to be made of next of kin. Another example of enhancing an already existing system is the program for colon cancer screening, which all Danes between 50 and 74 years are offered. Through sundhed. $\mathrm{dk}$, it is possible to opt out of this screening.

Third, sundhed.dk also utilizes and repurposes already familiar infrastructures for their users. For example, authentication that citizens are familiar with from banking and other public electronic service was introduced in 2009 (i.e., NemID). By exploiting an authentication method, which is available to and widely used by the Danish population, sundhed.dk is readily available to the Danes.

Although existing data sources, systems, and registries are repurposed through the e-health portal, the organization behind sundhed.dk avoids "data management" responsibilities. Rather, the solutions and data repositories which sundhed.dk links to or integrates with are themselves responsible for data management. For example, if the user has questions regarding data presented via sundhed.dk, the entities in the health service, which provided the health service and subsequently health data, are the point of contact. The role sundhed.dk has had in terms of being a public, authoritative site on health without having any form of responsibilities for the data displayed was "new turf' (head of administration, sundhed.dk). The fact that Danish health authorities have a long tradition of registering data and providing local health services challenges the repurposing and enhancing of existing data on the portal. For example, the partners have started to discuss and agree upon who owns what and how (representative, SSI).

Furthermore, the repurposing and enhancing of existing healthcare services has gradually changed the way in which partners perceive the organization behind the e-health portal. They have started to question the role of the portal and they voice their critique of sundhed.dk for not having ensured that its strategy is aligned with that of the partners. They question the overall direction of the portal: "It seems that it is the jukebox principle that defines what services are developed. To us it is not clear what are the criteria for prioritizing services... the strategy is not clear and sometimes I wonder if the strategy is technically driven in the sense of 'we have this new thing' and then they build it without any overarching strategy" (representative, the regions). For sundhed.dk, establishing a clear strategy is further challenged by the fact that there is not one common strategy for healthcare in Denmark: "It gets really complicated when you have so many strategies in play - the Digitization Strategy and the Healthcare Digitization Strategy at a national level, the Healthcare IT Strategy at a regional level, and then the municipalities have their own strategy" (head of administration, sundhed.dk). Whereas there is a common understanding of the overall vision of sundhed.dk, the existing ideas and strategies among the partners seem to be difficult to reconcile. In addition, partners question whether a regional strategy is more important compared to a national initiative. These concerns reflect the third mode of capitalizing on the installed base, which has to do with the engagement of multiple stakeholders, as we discuss next. 


\subsubsection{Engage Multiple Stakeholders}

The governing bodies and financing partners of sundhed.dk consist of members from Denmark's five regions, the Danish Regions, the Municipal Organization, and the Ministry of Health. This broad representation of key actors gave legitimacy to the portal at an early stage: "The purpose was to establish a common public healthcare portal [...] that vision was crucial, and then of course it was important that they managed to engage the most influential partners, such as Danish Regions, that primarily runs sundhed.dk, together with the municipalities and the Ministry of Health as partners" (representative, The Ministry of Health). In addition, informants describe it as a clear advantage that the organization of the governing bodies resembles the way in which the remaining healthcare system is organized. For example, the relationship between the regions, the government, and GPs has been maintained through general agreements: "The collaboration model we find in the Danish healthcare system is reflected in the organization of sundhed.dk. I believe that if we wouldn't have had this organization in place, it would have been very difficult to establish sundhed.dk" (representative, the regions).

The initial phase of sundhed.dk can be characterized as a political showcase for regional collaboration with solid political unity and common ambition. The involved parties have largely gathered around the common ambition of having one access point to the healthcare services: "At the outset, there was a clear vision, which was politically anchored in the Association of County Councils - one entrance point to healthcare services and cross-sectorial collaboration - it was a vision we all could agree upon" (head of administration, sundhed.dk). In addition: "We were told that if we could find a project that could strategically mark the 14 counties across, and not as silos, we would receive funding" (representative, the regions). In the initial phase, there was little disagreement concerning what should be offered to citizens and healthcare providers. The political unity and broad collaboration of stakeholders was described as key reasons for the success of the portal.

While there was a clear political mandate and a broadly agreed-upon vision, the partners had different starting points in terms of already existing digital services. One of the initial challenges was to get everyone at the same level: "It was a great opportunity to establish cross-sectorial collaboration, but this was also one of the biggest challenges [...] For example, not all regions had very advanced webpages" (head of administration, sundhed.dk). In addition, it was a challenge to get everyone onboard: "In the beginning, a lot of partners were happy about sundhed.dk and many believed in the overall vision. But if a region was working on a local project, it was difficult to get its buy-in. We spent much time in the beginning to go out locally and defend our existence. There was no choice for opting out. We basically told them that they themselves had decided that we should exist" (head of administration, sundhed.dk). The engagement of multiple stakeholders did not come automatically but had to be enabled actively by the staff at sundhed.dk. It was important to engage actors, since sundhed.dk did not have any authoritative responsibility or obligations. The overall purpose was to make services available and to establish 
editorial access to more than 900 partners over time. The role of sundhed.dk was to engage and, at the same time, control the partners. This was considered a "...difficult balancing act for sundhed.dk" to get the regions and municipalities to engage and own the process while at the same time manage and coordinate the efforts (representative, the regions).

Building on the installed base of a core set of actors was in this case a doubleedged sword, as one of the informants also stated; "What is their [sundhed.dk] strength is also their weakness" (representative, SSI). The informant here is referring to the broad alliance of partners, which gave the organization and e-health portal legitimacy, but also made it heavy and inflexible in the sense that many considerations were required for every decision. For example, the prioritization of tasks was described as a politicized decision-making process: "It is very difficult to be sundhed.dk in terms of serving so many masters" (representative, Ministry of Health). The head of administration in sundhed.dk further elaborated on the challenges in decision-making and prioritization processes: "We cannot prioritize projects ourselves [internally in sundhed.dk]. We need to do that in collaboration with our partners. They have their own interests and local benchmarks and we don't have resources to financially support all their wishes". This situation put sundhed. $\mathrm{dk}$ in a certain bind. In addition, priorities seemed to shift after certain tasks had been initiated, thus making the daily development of new services cumbersome: "You can risk that when the economical agreements are made, a politician will suddenly say 'Now we need more people to donate their organs, so in 2013 this should be registered on sundhed.dk'. This was not how it was earlier - we knew very well what we needed to do. Now our partners often want to lift their IT-strategies and projects via the portal" (head of administration, sundhed.dk). Although it complicates development when having to accommodate all partners' needs and IT strategies, it is encouraged and part of sundhed.dk's overall mission.

Overall, there has been broad support from relevant players in the Danish healthcare arena, but at the same time, it has been challenging for the sundhed.dk organization to serve so many masters. As time passed, the majority of actors started to question what was in it for them. The regions, who financed $80 \%$ of sundhed.dk, wanted to see their requests being realized: "When we pay for a service, we also assume that it will appear on the portal" (representative, the regions). In particular in 2009, when sundhed.dk decided to do most development of services in-house as opposed to development by external consultants, it was a challenge for them to keep up with the pace of demands since "the pipeline was getting too tight" (head of administration, sundhed.dk). A representative from one of the regions, who argued that the production line was too limited with the consequence of delayed projects, confirmed this observation: “... there has been a shift from being a client to being a vendor, and this has been a challenge for sundhed.dk. Mostly because the production line has become very narrow [...] and there has been too many things that have been important for the regions, but we don't want to constantly discuss prioritizing those services that are included on sundhed.dk" (representative, the regions). The request for the future was that the organization behind sundhed.dk would be able to develop projects in parallel. 
In the next section, we conclude the chapter by discussing the findings and reflecting upon the future of sundhed.dk.

\subsection{Discussion: Moving Forward}

What makes the sundhed.dk case unique is the mobilization of a large number of stakeholders. Sundhed.dk has managed to cultivate a large network of alliances, which makes it successful and at the same time difficult for other countries to replicate. As we demonstrated in the analysis, the engagement of multiple stakeholders did not come automatically. Although the initiation of the portal came with a political mandate, sundhed.dk still had to engage actively the different stakeholders. It is fascinating to see how the collaboration among different stakeholders made it possible to integrate divergent priorities and strategies into one shared portal. This conclusion is in line with previous research (e.g., Aanestad and Jensen 2011), which shows that the realization of nation-wide information infrastructures for healthcare not only requires a gradual transition of the installed base; the development also needs to ensure the mobilization and organization of multiple stakeholders.

However, it was not only the active engagement of stakeholders, which made sundhed.dk a success. The installed base in the form of pre-existing technologies, regulatory frameworks, data resources, and organizational arrangements played a key role in the gradual evolution of sundhed.dk. The main reason for the current positioning of sundhed.dk was its ability to collate and assemble existing data resources, and also to repurpose and enhance current data sources in the health sector.

Taken together, these activities were important for sundhed.dk in order to capitalize on the installed base. At the same time, however, the organization now faces a number of challenges in staying relevant for its partners in the time ahead. While the portal was very visionary at the beginning, it could easily get behind regarding current trends in a fast moving sector of digital health services. Large leaps are being made in fields such as mobility and "quantified self," whereby patients provide data about themselves either manually or through sensors and this leads to high demands from society, and the younger generations specifically, on how services are offered digitally. Additionally, as new digital systems are being introduced in the health service in the regions in Denmark, sundhed.dk needs to be aligned with these changes. For example, at the time of writing, the regions in and around the capital are introducing EPIC as an all-encompassing suite for the tertiary health service (Jensen 2016), and sundhed.dk needs to link up with these new data sources and providers.

To stay relevant over time, sundhed.dk also needs to broaden its capacity to develop services at a pace that is needed for the involved partners. This could mean easing the possibility for external developers to create services and having a flexible governance structure and an agile development methodology. These measures 
should, at the same time, be balanced with measures to ensure that quality and professionalism are not compromised. These are issues that sundhed.dk are working on at the time of writing. A program, targeting the above-mentioned challenges, has led to a reorganization of sundhed.dk to ensure increased delivery capacity and stronger portfolio management. In the future, focus is on being proactive and assist the partners in developing and maturing new service concepts. According to sources at sundhed.dk, this work yields positive results.

Lastly, without any formal mandate, sundhed.dk has to keep a balance between being a receiving part, acting on their partners' wishes, while at the same time contributing to a clear direction within the Danish healthcare sector. This is the main premise of the organization behind sundhed.dk, which has led to the evolution of the e-health portal, but now needs to show the future direction of the portal.

\section{References}

Aanestad M, Jensen TB. Building nation-wide information infrastructures in healthcare through modular implementation strategies. J Strateg Inf Syst. 2011;20(2):161-75.

Danish Regions. IT brings the Danish health sector together. In: Danish Regions, M., Sundhed.dk, Digital Health, Local Government Denmark (Ed.). Copenhagen.2010.

Jensen TB. Design principles for achieving integrated healthcare information systems. Health Inform J. 2013;19(1):29-45.

Jensen TB. The Danish IT healthcare platform: real-time hospital management, In: Cases on IT Leadership: CIO Challenges for Innovation and Keeping the Lights on, Niels Bjørn-Andersen, editor. 2016. Samfundslitteratur: 217-236

Lynge E, Sandegaard JL, Rebolj M. The Danish national patient register. Scand J Publ Health. 2011;39(7 suppl):30-3.

NemID. Statistik om NemID, Digitaliseringsstyrelsen. 2014.

Pedersen, K. M., Andersen, J. S. and Søndergaard, J. General Practice and Primary Health Care in Denmark, Journal of American Board of Family Medicine 2012;25: 34-38.

Protti, D. and Johansen, I. Widespread Adoption of Information Technology in Primary CarePhysician Offices in Denmark: A Case Study, Issues in International Health Policy, TheCommonwealth Fund 2010: 1-14

Sundhed.dk. Recognition to sundhed.dk. https://www.sundhed.dk/borger/service/nyt-og-presse/ presserum/pressemeddelelser/. 2014a. Accessed on the January 2017.

Sundhed.dk. Press Room. https://www.sundhed.dk/borger/service/om-sundheddk/om-organisationen/. 2014b. Accessed on January 2017.

Sundhed.dk. About the Organization. https://www.sundhed.dk/borger/service/om-sundheddk/omorganisationen/. 2016. Accessed on January 2017.

The Danish Government, Danish Regions and Local Government Denmark. National strategy for digitalization of the healthcare service. https://www.sundhed.dk/content/cms/6/3406_nationalstrategi-2008-2012.pdf. 2008. Accessed on November 2014.

The Danish Government, Danish Regions and Local government Denmark. Making e-Health work. National Strategy for Digitalization of the Danish Healthcare Sector 2013-2017, The Danish Government, Copenhagen. 2012.

Thorseng A, Jensen TB. Building national infrastructures for patient-centred digital services. In: 23rd European Conference on Information Systems (ECIS), Münster. 2015. 
Open Access This chapter is distributed under the terms of the Creative Commons AttributionNonCommercial 2.5 International License (http://creativecommons.org/licenses/by-nc/2.5/), which permits any noncommercial use, duplication, adaptation, distribution and reproduction in any medium or format, as long as you give appropriate credit to the original author(s) and the source, provide a link to the Creative Commons license and indicate if changes were made.

The images or other third party material in this chapter are included in the chapter's Creative Commons license, unless indicated otherwise in a credit line to the material. If material is not included in the chapter's Creative Commons license and your intended use is not permitted by statutory regulation or exceeds the permitted use, you will need to obtain permission directly from the copyright holder. 